\begin{tabular}{lcl}
\hline Bentham open & The Open Parasitology Journal \\
CrossMark & Content list available at: www.benthamopen.com/TOPARAJ/ & DOI: $10.2174 / 1874421401806010007$ \\
\hline
\end{tabular}

RESEARCH ARTICLE

\title{
Clinical and Hematological Profiles of Malaysian Ponies Experimentally Infected with a Field Strain of Trypanosoma evansi
}

\author{
E.I. Elshafie ${ }^{1, *}$, R.A. Sani $^{2}$, R. Sharma ${ }^{2}$ and I.A. Abubakar ${ }^{3}$ \\ ${ }^{\text {I}}$ Central Veterinary Research Laboratory, Al Amarat, P.O. Box 8076, Khartoum, Sudan \\ ${ }^{2}$ Faculty of Veterinary Medicine, University Putra Malaysia, 43400 Selangor, Malaysia \\ ${ }^{3}$ Faculty of Veterinary Medicine, Usmanu Danfodiyo University, Sokoto, Nigeria
}

Received: February 21, 2018

Revised: April 23, 2018

Accepted: May 8, 2018

\begin{abstract}
:
Background:

No outbreak has been reported on Trypanosoma evansi infection in Malaysia ponies since 1983, and little is known about the interaction between $T$. evansi and ponies in the country. Therefore, an experimental study was designed to evaluate the pathogenicity of a local strain of $T$. evansi in the local ponies.
\end{abstract}

\section{Method:}

For this purpose, four healthy local ponies were inoculated with $10^{2}$ live trypanosomes/kg body weight, whereas two ponies served as negative control. Blood samples and rectal temperature were collected on alternate days from both groups for 54 days. Physical examination comprised visible mucous membrane and any appearance of clinical signs were observed daily. The number of trypanosomes was estimated using the Neubauer haemocytometer method. Complete haemogram measurements were performed immediately using an automated blood cell counter and the data obtained was evaluated using the general linear model as linear regression. All infected ponies were salvaged treated with $7 \mathrm{mg} / \mathrm{kg}$ of diminazene diaceturate.

\section{Results:}

The four infected ponies developed parasitaemia on the $4^{\text {th }}$ day post-infection (DPI), whereas the first high mean of parasites count was recorded on the $8^{\text {th }}$ DPI. Parasitaemia was detected at a level that fluctuated throughout the infection period ( 30 days) in all infected ponies with a mean of $13.5 \times 106$ trypanosomes $/ \mathrm{ml}$ blood on the $30^{\text {th }}$ DPI. Successive peaks of pyrexia were accompanied by the peaks of parasitaemia and the highest temperature $\left(39.4^{\circ} \mathrm{C}\right)$ was observed on the $20^{\text {th }}$ DPI. Excessive weakness and a reduction of appetite fluctuated in the infected ponies during the infection and one animal died unexpectedly on the $23^{\text {rd }}$ DPI. The mean values for $\mathrm{RBC}, \mathrm{PCV}, \mathrm{Hb}$ and thrombocyte count were significantly lower in the infected ponies than the control groups. Neutrophil and eosinophil were significantly declined after the onset of parasitaemia, whereas monocyte increased significantly in the infected group.

\section{Conclusion:}

The appearance of clinical signs and changes in haematological parameters suggests that Malaysian local ponies are susceptible to $T$. evansi infection. Treatment of the infected ponies with the recommended dosage of diminazene diaceturate was successful in the surviving ponies.

Keywords: Experimental infection, Malaysian ponies, Trypanosoma evansi, Parasitaemia, Haematology, Anaemia.

* Address correspondence to this author at the Central Veterinary Research Laboratory, Al Amarat, P.O. Box 8076, Khartoum, Sudan; Tel: 00249125253961; E-mail: shifoo40@yahoo.com 


\section{INTRODUCTION}

The ability of $T$. evansi to induce a severe surra in different hosts depends mainly on a number of factors, including the virulence of an individual strain, host susceptibility and local epizootiological conditions. Horses, dogs and camels are reported to be the most susceptible hosts of $T$. evansi infection, developing an acute disease characterized by anaemia and high mortality if treatment is not administered [1]. The course of the disease in the horse is characterized either by acute phase for a short duration of two weeks or a chronic phase extending up to four months. In the acute stage, after incubation of one or two weeks, animals developed fever, anaemia, weakness and lethargy with high parasitaemia in circulating blood [2]. A recent experimental study from India indicated that ponies succumbed to $T$. evansi infection with death and neurological symptoms [3]. Anaemia is the most common feature of the infection in ponies while white blood cells (WBCs) have not shown a definite trend. On the other hand, lower surra outbreak occurrences in animals accompanied with a lesser disease severity in Southeast Asian countries may indicate a form of enzootic stability achieved by some susceptible animals [4]. In addition, Horse as reservoir hosts was highlighted in Brazil [5]. The study found an absence of neurological symptoms with a high prevalence rate accompanied by low parasitaemia detected only by PCR in ponies during field surveys. An experimental infection of T. evansi in ponies in Brazil conducted by Marques et al. [6] indicated an expression of neurological symptoms on $50 \%$ of the animals on the $77^{\text {th }}$ DPI with one case of death on $66^{\text {th }}$ DPI, an indication of chronic stage of the disease. In Malaysia, the dynamics of T. evansi infection has been studied in naturally infected local ponies [7,8]. The results obtained from the two studies reported similar clinical signs and death as observed in other studies in different parts of the world [9, 10]. Recently, a cross-sectional study aimed to determine the prevalence of $T$. evansi in Malaysian ponies indicated a relatively low seroprevalence of $13.90 \%$ (73/527, CI: 11.2-17.1\%) [11] and a parasitological prevalence of $1.14 \%$ (6/527, CI: 2.4-0.52\%) using PCR [12]. Thus, we hypothesized that the Malaysian ponies may either develop a tolerance or severe illness against $T$. evansi infection. Therefore, in the present study, the dynamics of $T$. evansi infection was investigated in experimentally infected Malaysian ponies with emphasis on clinical signs, parasitaemia trend and haematological parameters.

\section{MATERIALS AND METHODS}

\subsection{Experimental Animals}

Six healthy female local ponies, aged between three to seven years were obtained from the Equine Unit, University Putra Malaysia, the location was assumed historically free of T. evansi infection by University Veterinary Hospital. The ponies were initially tested with haematocrit centrifugation technique (HCT), Giemsa-stained thin blood smear, CATT/T. evansi and PCR to ascertain that they were free of T. evansi and other blood protozoa. The ponies were kept in a fly-proof isolation unit during the experimental period of 54 days. Before the start of the experiment, the ponies were conditioned for one month at the unit and dewormed with benzimidazole, food and water were provided ad libitum.

\subsection{T. evansi Isolate and Experimental Design}

A T. evansi strain isolated from a local pony [12] was propagated through two passages, in two mice per passage. When the level of parasitaemia was high (exceeding $10^{6}$ trypanosomes $/ \mathrm{ml}$ ), the mice were euthanized and cardiac blood was used. The ponies were allocated randomly into two groups based on their body weight. Four of them were received approximately $10^{2}$ live trypanosomes/kg body weight suspended in $1 \mathrm{ml}$ phosphate buffer saline glucose (PBSG) via the jugular vein. The remaining two animals served as negative control and received a placebo of $1 \mathrm{ml}$ of PBSG without the parasite. Physical examination comprised visible mucous membrane and appearances of clinical signs were observed daily, while body weight was estimated weekly. Blood samples from the jugular vein and rectal temperature were collected on alternate days from both the groups for 54 days; 4 days before infection, 30 DPI and 20 days post-treatment (DPT). Blood samples for haematology and parasitological techniques were collected into vacutainer tubes containing EDTA.

\subsection{Detection of Trypanosomes, Enumeration and Haematology Variables}

The HCT was applied to detect the presence of Trypanosoma evansi in the blood of the experimental animals as described by Woo [13]. The number of trypanosomes was estimated using the Neubauer haemocytometer method by counting the four large corner squares under objective $\mathrm{x} 400$. When the parasitaemia was low and could not be counted by the haemocytometer, another method was employed as described by Wernery et al. [14]. No other diagnostic 
techniques were applied.

Complete haemogram was performed immediately upon blood collection. The parameters include total RBC, total WBC, platelet counts and $\mathrm{Hb}$ concentration, which were measured using an automated blood cell counter (Abbott Cell Dyn 3700, USA). Packed cell volume (PCV) was measured using a manual haematocrit reader. The differential leukocyte counts were obtained from smears stained with Wright stain (Sigma Chemical Company, USA). The mean corpuscular haemoglobin concentration (MCHC) and mean corpuscular volume (MCV) were also calculated.

\subsection{Animal Treatment and Follow-up}

All infected ponies were salvaged treated with $7 \mathrm{mg} / \mathrm{kg}$ of diminazene diaceturate (Diminasan ${ }^{\circledR}$, Holland) intramuscular injection on the $31^{\text {st }}$ DPI with booster doses to enhance permanent cure $[15,16]$. Sampling was continued with the same regime of alternate days for another 20 DPT after the first dose. Survived ponies were monitored on a weekly basis for six months to warrant the clearance of the infection.

\subsection{Data Analysis}

The normal range of values for haematology of ponies was obtained from Pritchard et al. [17]. The graph drawings and statistical tests were performed using JMP version 9.0 (SAS Institute Inc. USA) with an absolute precision of $\pm 5 \%$ for a 95\% confidence interval. The continuous data obtained from haematological observations between infected and control groups during the infection period (30 days) were evaluated using the general linear model. Haematological parameters such as thrombocyte, MCV, MCHC, neutrophil, monocyte and eosinophil count were transformed using a bootstrap method to fit the assumption of normality. The mean values (intercept) of the parameters for each group were reported as least square means \pm standard error, whereas the regression coefficient for dummy variable was reported as $\beta$.

\section{RESULTS}

\subsection{Parasitaemia and Pyrexia}

All four infected ponies developed parasitaemia on the $4^{\text {th }}$ DPI $\left(2.5 \times 10^{4}\right.$ trypanosomes $/ \mathrm{ml}$ blood $)$ as detected by HCT, whereas the first high mean parasites count $/ \mathrm{ml}$ was recorded on the $8^{\text {th }}$ DPI $\left(22.5 \times 10^{6}\right.$ trypanosomes $/ \mathrm{ml}$ blood $)$. Parasitaemia was detected at a level that fluctuated throughout the infection period (30 days) in all infected ponies with a mean of $13.5 \times 10^{6}$ trypanosomes $/ \mathrm{ml}$ blood on the $30^{\text {th }}$ DPI. No parasites were detected by HCT on the second day after treatment $\left(32^{\text {nd }} \mathrm{DPI}\right)$ and throughout the observation period in the infected ponies. The mean rectal body temperature rose concurrently with the parasitaemia and observed firstly on the $4^{\text {th }}$ DPI $\left(38.9^{\circ} \mathrm{C}\right)$. Successive peaks of pyrexia were aligned to the peaks of parasitaemia and the highest temperature $\left(39.4^{\circ} \mathrm{C}\right)$ was observed on the $20^{\text {th }}$ DPI (Fig. 1). The control group did not show parasitaemia or pyrexia during the study period.

\subsection{Clinical Observation}

The morbidity rate observed in the infected group during the infection period was $100 \%(4 / 4)$, whereas the mortality rate was $25 \%(1 / 4)$, the infected ponies showed a mean weight loss of $7 \%$ over the infection period. Pale mucous membrane of the eyes and vagina were noticed between the $14^{\text {th }}$ and $18^{\text {th }}$ DPI. Excessive weakness and a reduction of appetite fluctuated in the infected ponies during the infection which did not correspond to the pyrexia and parasitaemia. One animal died on the $23^{\text {rd }}$ DPI, the parasite count $/ \mathrm{ml}$ and PCV were $44 \times 10^{6}$ and $14 \%$ respectively, on the day before death.

\subsection{Haematological Observations}

The mean values for $\mathrm{RBC}$ count, $\mathrm{PCV}$ and $\mathrm{Hb}$ concentration were significantly lower in the infected than the control groups $(\beta=-1.57, \mathrm{t}=11.80, \mathrm{p}<0.05 ; \beta=-4.15, \mathrm{t}=10.34, \mathrm{p}<0.05 ; \beta=-19.58, \mathrm{t}=55.02, \mathrm{p}<0.05$, respectively) firstly, on the 16th DPI (Fig. 2). The mean values of thrombocyte count in the infected ponies $(113.06 \pm 1.42$ $\mathrm{x} 10^{9}$ cells $\left./ \mathrm{L}\right)$ was significantly $(\beta=-72.83, \mathrm{t}=59.06, \mathrm{p}<0.05)$ lower than the control group $(258.73 \pm 2.01$ $\left.\mathrm{x} 10^{9} \mathrm{cells} / \mathrm{L}\right)$. The mean MCV significantly increased in the infected group compared to the non- infected group $(\beta=$ $3.33, \mathrm{t}=47.22, \mathrm{p}<0.05)$ while, a significant decrease was observed in the mean MCHC values in the infected group compared to the control group in $(\beta=-11.71, \mathrm{t}=18.02, \mathrm{p}<0.05)$. However, both values of MCV and MCHC in the infected group were within the normal values, and hence the anaemia observed was classified as normocytic 
normochromic anaemia (Fig. 2).

Total WBC counts were not statistically significant between infected and control ponies $(\beta=-0.49, \mathrm{t}=1.89, \mathrm{p}>$ $0.05)$. Neutrophil rapidly declined after the onset of parasitaemia and it was significantly lower in the infected group (4 $\left.\pm 0.03 \times 10^{9} / \mathrm{L}\right)$ than the control group $\left(5.40 \pm 0.05 \times 10^{9} / \mathrm{L}\right)(\beta=-0.7, \mathrm{t}=23.6, \mathrm{p}<0.05)$. Monocyte mean value increased significantly $(\beta=0.35, \mathrm{t}=33.99, \mathrm{p}<0.05)$ after successive peaks of parasitaemia in the infected group $(1.17$ $\left.\pm 0.01 \times 10^{9} / \mathrm{L}\right)$ compared to the control group $\left(0.48 \pm 0.02 \times 10^{9} / \mathrm{L}\right)$, whereas eosinophil declined $(\beta=-0.06, \mathrm{t}=29, \mathrm{p}<$ $0.05)$ (Fig. 3). There was no significant difference in mean lymphocyte counts $(\beta=-0.16, \mathrm{t}=1.33, \mathrm{p}>0.05)$ and mean basophil counts $(\beta=0.003, \mathrm{t}=0.56, \mathrm{p}>0.05)$ between infected and non-infected ponies (Fig. 3).

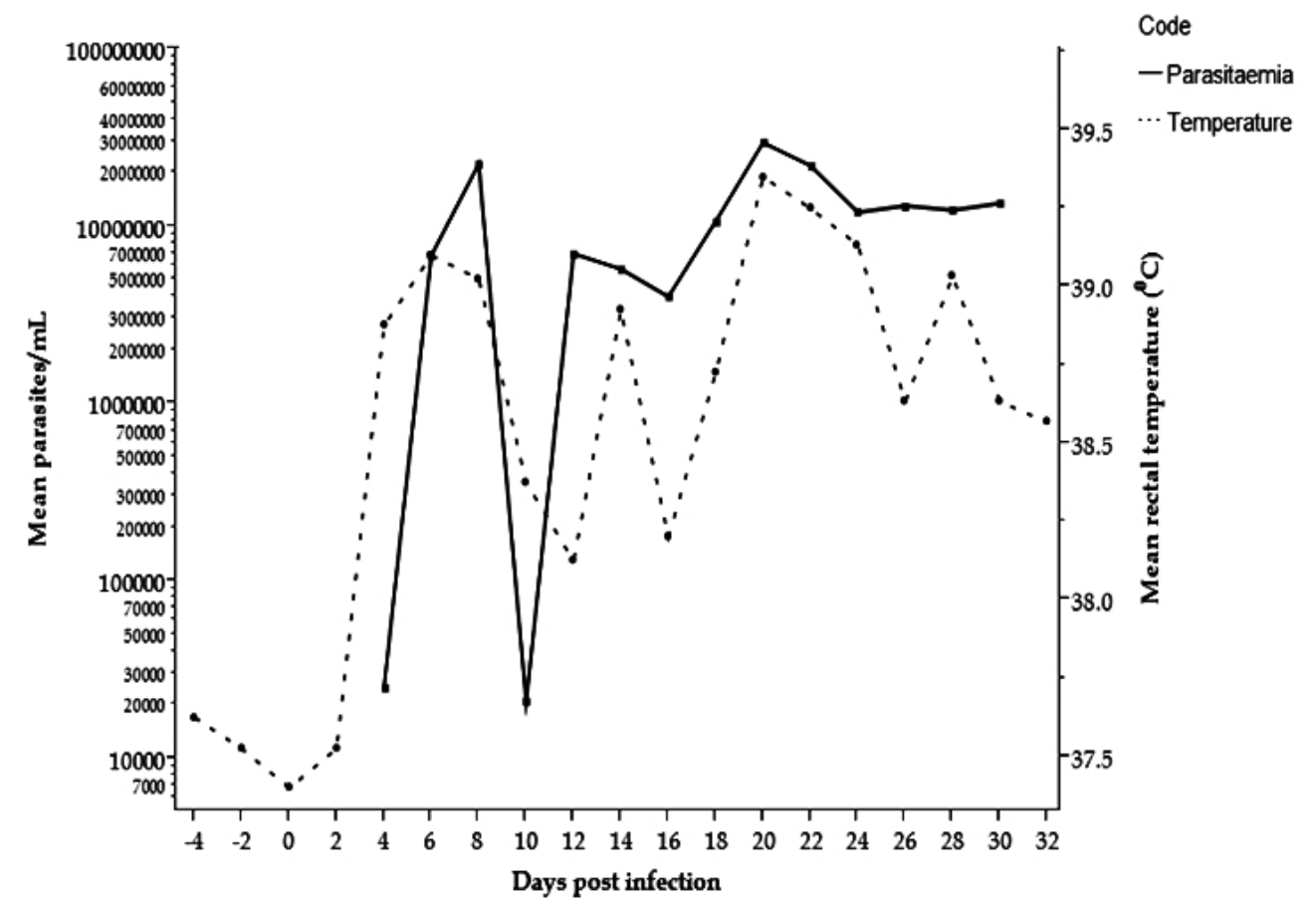

Fig. (1). Mean parasitaemia and pyrexia observed during the course of $T$. evansi infection in four local ponies. Normal rectal temperature is $36.6-38.6^{\circ} \mathrm{C}$.

\section{DISCUSSION AND CONCLUSION}

Clinical and Haematological measurements involved in trypanosomosis infection studies aid in determining the health status of animals under investigation [18]. T. evansi infections in different experimental and natural infection studies in horses range from mild to severe. The majority of the infection was characterized by high mortality if the animal is not treated or even after treatment $[7,6]$. T. evansi was first detected on the $4^{\text {th }}$ DPI in the four infected ponies, followed by waves of successive peaks of parasitaemia throughout the infection period of 30 days. The undulating parasitaemia developed in order to protect the parasites from the host immune system by changing the surface coat, once the previous one is attacked by the host defence mechanism [19]. According to Wernery et al. [14], horses experimentally infected with approximately $3 \times 10^{6} T$. evansi showed parasites in blood on the $1^{\text {st }}$ and $3^{\text {rd }}$ DPI, whereas Marques et al. [6] reported it on the $4^{\text {th }}$ DPI with $1 \times 10^{6} T$. evansi. Therefore, the detection of the parasites on $4^{\text {th }}$ DPI in the current study may be due to the low dosage of parasite used to initiate the infection. Rectal body temperature trend paralleled the parasitaemia and fluctuated during the infection, and this finding is in agreement with a previous observation [9]. However, after treatment, the pyrexia declined to the values of the control group and the pre-infection period as an indication of removal of the causative agent. In this study, diminazene diaceturate seems to effectively eliminate $T$. evansi at the recommended dose of $3.5 \mathrm{mg} / \mathrm{kg}$ on the $31^{\text {st }}$ DPI with booster doses after the $7^{\text {th }}$ DPT. There was no circulating or relapse of parasitaemia detected 24 hours after the $1^{\text {st }}$ treatment which is consistent with the earlier report by Tuntasuvan et al. [16]. 


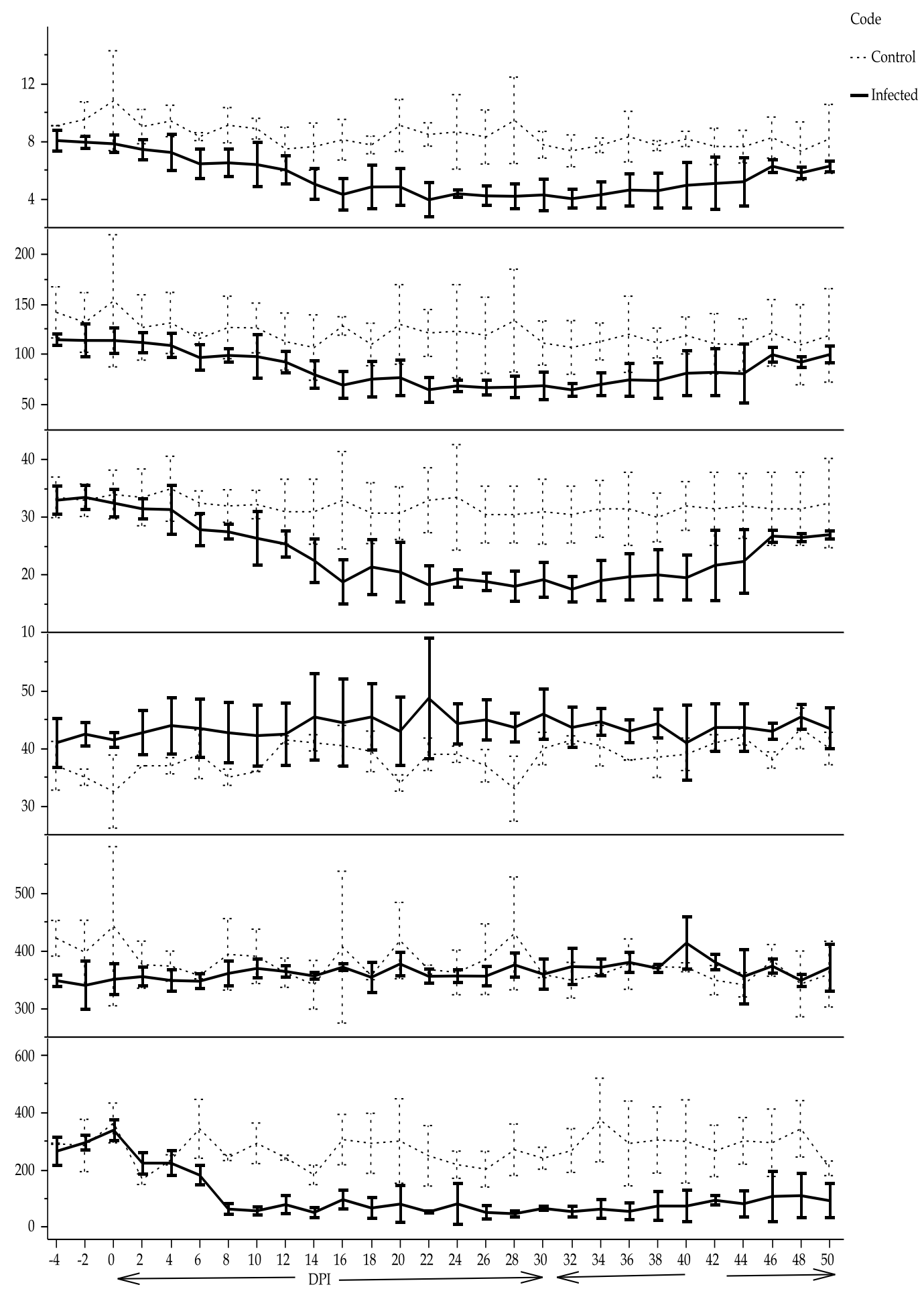

Fig. (2). Mean total RBC, Hb, PCV, MCV, MCHC and thrombocyte values of ponies experimentally infected with $T$. evansi: DPI = days post-infection (0-30), DPT $=$ days post-treatment (31-50). 


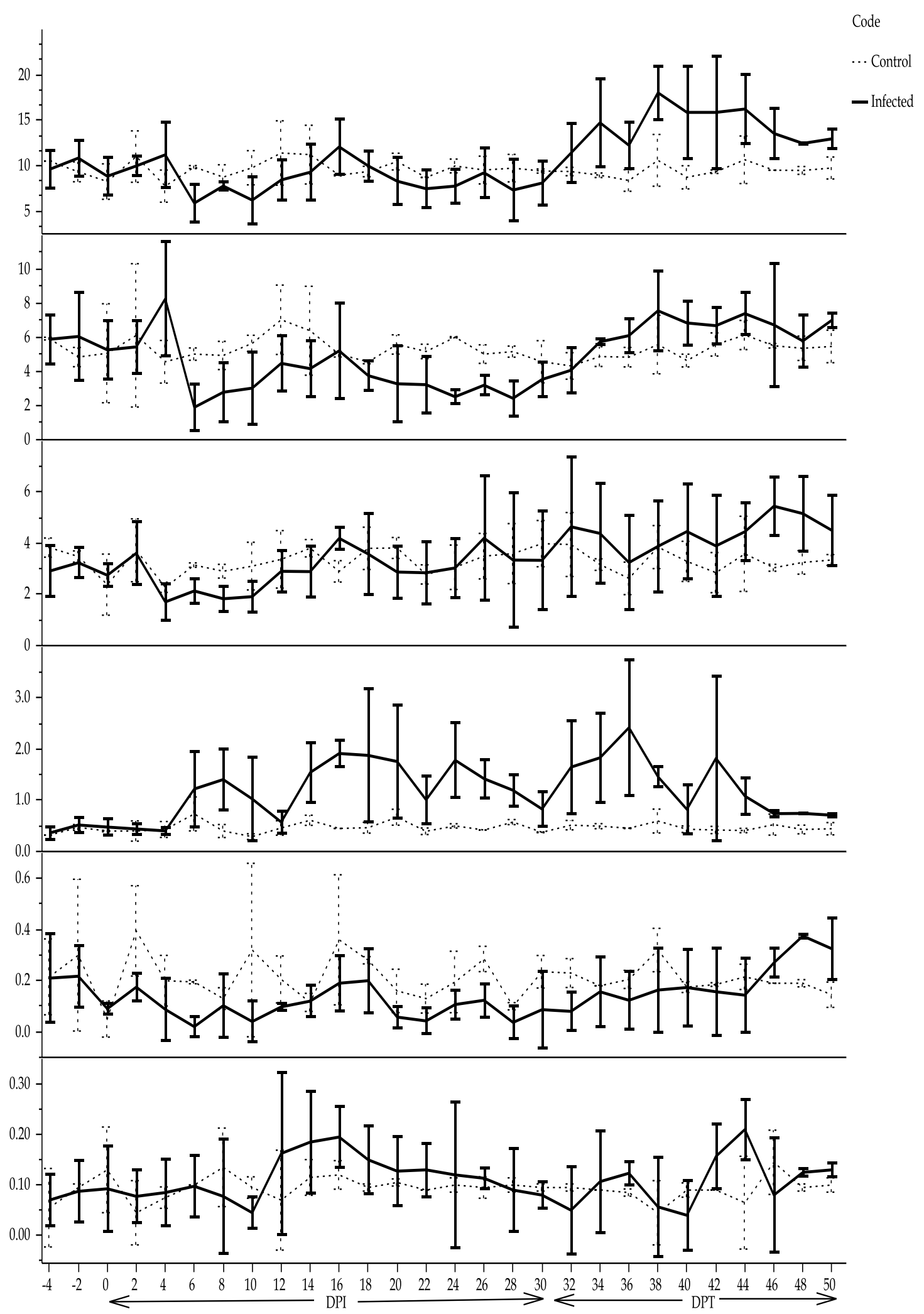

Fig. (3). Mean total WBC, neutrophil, lymphocyte, monocyte, eosinophil, basophil counts of ponies experimentally infected with $T$. evansi: DPI = days post-infection (0-30), DPT = days post-treatment (31-50). 
The clinical signs observed in this study comprised body weight loss, pale mucous membrane, excessive weakness and reduction of appetite which was not related to the parasitaemia and pyrexia. Similar findings were reported in both experimentally [14] and naturally infected horses [7]. According to Wernery et al. [14] the weight of horses experimentally infected with $T$. evansi was reduced by $10-15 \%$ over a period of eight to nine months. Therefore, the relatively low body weight loss of $7 \%$ in the local ponies during our study may probably be associated with short duration of infection. Marques et al. [6] indicated that the inoculation of $1 \times 10^{6}$ trypomastigote per horse isolated from a dog in Brazil induced an infection for 77 days with death occurring in one horse on the $66^{\text {th }}$ DPI and $50 \%$ of the horses expressed neurological symptoms on the $77^{\text {th }}$ DPI. It seems possible that the severity of the disease with the short duration of $T$. evansi infection in our study is either due to the highly virulent $T$. evansi strain existing in the country or local ponies are highly susceptible to $T$. evansi infection, since Ikede et al. [8] observed high mortality in naturally infected horses with T. evansi in Peninsular Malaysia.

T. evansi is known to disseminate to the CNS in infected horses as the parasites have been isolated from the CSF [10]. The absence of nervous signs in our study was probably due to the short duration of the infection as speculated by Hörchner et al. [9]. They concluded that behavioural changes in the horses experimentally infected with $T$. evansi were very minor during the first four weeks of infection. The neurological sign as indicated by paralysis of the hind quarter was reported in horses [6] and incoordination of the hind quarter was also observed by Yadav et al. [3]. One horse died unexpectedly on the $23^{\text {rd }}$ DPI in the current study. Despite the pale emaciated carcass of the horse, the cause of death could not be explained as the post-mortem finding of the internal organs was insignificant. However, high parasitaemia accompanied by low PCV value was noticed one day before the animal died, which may explain the severity of the disease as the main cause of death. These findings of the current study are consistent with those of Hörchner et al. [9] who reported the inability of post-mortem findings in determining the cause of death in horses acutely infected with $T$. evansi. Rapid decline in mean values of RBC counts, $\mathrm{PCV}$ and $\mathrm{Hb}$ concentrations are observed in infected horses on the $16^{\text {th }}$ DPI onward. However, these values returned to values similar to that of the control group after treatment. Anaemia has been reported by several authors as main findings of $T$. evansi infection [20,14, 21). A study on $T$. vivax in Brazil indicated development of anaemia with mortality in some naturally infected horses [22]. The origin of anaemia in animals infected with $T$. evansi is not well understood. It was speculated that the extra-vascular haemolytic anaemia accompanying $T$. evansi infection may be attributed to the rapid removal of RBC from the circulation by macrophages as a consequence of an immune-mediated mechanism adopted by $T$. evansi antigen-antibody complexes [23]. Another possible reason for the anaemia is increased of lipid peroxidation, which may reduce the ability of RBC to prevent its membrane from destruction due to oxidative changes in the acute phase of $T$. evansi infection [24]. Therefore, the anaemia observed in the local ponies in the current study was not a surprising result.

Despite the significantly elevated values of MCV and the decreased values of MCHC in the infected group in the current study, it is still within the normal range. Pritchard et al. [17] stated the normal range for MCV and MCHC as 43.9-55.6 fl and 331-369 $\mathrm{g} / \mathrm{L}$ respectively. Therefore, the normocytic normochromic anaemia observed here is consistent with other reports of anaemia in horses and donkeys with trypanosomaisis [7, 21]. In contrast, trypanotolerant sheep and goats from Gambia artificially infected with Trypanosoma congolense revealed a macrocytic hypochromic and normocytic normochromic anaemia respectively, during the acute phase of the infection (12 weeks) [25]. After this period the haematological findings indicated regeneration of erythropoiesis. The author concluded that, both animal species are resistant to the infection. However, the sheep erythropoietic response was better than the goat in controlling anaemia produced by the infection. Thrombocytopenia is clearly seen in this study. The decrease in platelet count is in agreement with Stephen [26], who explained that the mediated immunological mechanism is responsible for removal of platelets by phagocytes and destroyed in organs such as spleen and liver. In addition, the decrease of platelet count was inversely associated with the successive production of parasites in cattle experimentally infected with Trypanosoma congolense [27].

No significant difference was observed between the infected and non-infected groups with regard to the mean values of the complete WBC, lymphocyte and basophil counts. However, the total leukocyte and lymphocyte counts initially declined after the infection and thereafter increased in the middle of the infection period. In contrast, a significant increase in monocyte counts and lowered neutrophil and eosinophil counts were seen in the infected group. The trend of leukocyte changes in horses experimentally infected with T. evansi is highly variable [6]. On the other hand, mild leucopoenia due to decline in neutrophil counts with relative lymphocytosis and monocytosis were reported in naturally infected horses with T. evansi [20]. Leucopoenia which observed in some animals infected with trypanosomes may be attributed to the reduction of myelopoiesis as a compensatory response to the exaggerated activity 
of erythropoiesis as indicated by Weiss and Wardrop [28].

Monocytosis was reported in artificial infection of T. evansi in horse [14]. The monocytosis observed in this study was probably due to the increase in phagocytic activities induced by $T$. evansi antigen-antibody complexes. The activation of the mononuclear phagocytic system during the infection in cattle with $T$. brucei or $T$. congolense plays a key role in enhancing the monocytes to engulf and digest the sensitised trypanosomes coated by specific IgM or IgG1 antibodies [29]. The neutropoenia observed in the current investigation is in agreement with Ohaeri and Eluwa [18] which suggested a decrease in neutrophil in ruminants infected by trypanosomes was due to exhaustive use of neutrophil as a consequence of inflammation. The decrease in eosinophil counts observed in the infected group was of little interest since normal values for this parameter can even reach zero in healthy horses [17]. However, leucopoenia accompanied with eosinopoenia was observed in dogs experimentally infected with T. brucei [30] and in crossbred calves infected with T. evansi [31].

Despite the small sample size used in the experimental infection, the dynamics of T. evansi infection in Malaysian local ponies demonstrated that Malaysian ponies are highly susceptible to the infection. The inoculum of 100 parasites/kg body weight established an acute infection of $T$. evansi with high morbidities and one case of death. Successive peaks of parasitaemia were generated during the infection period, and the animals were unable to suppress it. The main clinical findings were fever, weight loss, successive weakness, reduction of appetite and finally led to death. Furthermore, changes in haematology were noticed as normocytic normochromic anaemia. The treatment regime using diminazene diaceturate at the recommended dose twice at a week's interval successfully treated surviving ponies and the blood haematology parameters returned to the values similar to those in the control group.

\section{ETHICS APPROVAL AND CONSENT TO PARTICIPATE}

The research procedures involved in the current study were approved by the Institutional Animal Care and Use Committee (IACUC), Faculty of Veterinary Medicine, Universiti Putra Malaysia (UPM/FPV/PS/3.2.1.551/AUP).

\section{HUMAN AND ANIMAL RIGHTS}

No humans were used in the experiments. All the reported experiments involving animals used in the study were in accordance with the Institutional Animal Care and Use Committee (IACUC), Faculty of Veterinary Medicine, Universiti Putra Malaysia (UPM/FPV/PS/3.2.1.551/AUP).

\section{CONSENT FOR PUBLICATION}

Not applicable.

\section{CONFLICT OF INTEREST}

The authors declare no conflict of interest, financial or otherwise.

\section{ACKNOWLEDGEMENTS}

This study was supported by Agro-Biotechnology Institute, Ministry of Science, Technology and Innovation, Malaysia. Our thanks extended to the Parasitology staff, the staff of Veterinary Hospital and the staff of Equine Unit, University Putra Malaysia, for technical and logistical assistance during the study.

\section{REFERENCES}

[1] Hoare CA. The Trypanosomes of Mammals: A Zoological Monograph. Oxford: Blackwell Scientific Publications 1972.

[2] Losos GJ. Diseases caused by Trypanosoma evansi, A review. Vet Res Commun 1980; 4: 165-81. [http://dx.doi.org/10.1007/BF02278495]

[3] Yadav SC, Kumar J, Gupta AK, et al. Parasitological, biochemical and clinical observations in ponies experimentally infected with Trypanosoma evansi. J Exp Biol Agric Sci 2016; 4(Spl-4-EHIDZ): S144-50.

[4] Luckins AG. Trypanosoma evansi in Asia. Parasitol Today (Regul Ed) 1988; 4(5): 137-42. [http://dx.doi.org/10.1016/0169-4758(88)90188-3] [PMID: 15463067]

[5] Herrera HM, Dávila AM, Norek A, et al. Enzootiology of Trypanosoma evansi in Pantanal, Brazil. Vet Parasitol 2004; 125(3-4): 263-75. [http://dx.doi.org/10.1016/j.vetpar.2004.07.013] [PMID: 15482883]

[6] Marques LC, Machado RZ, Alessi AC, Aquino LPCT, Pereira GT. Experimental infection with Trypanosoma evansi in horses: Clinical and haematological observations. Rev Bras Parasitol Vet 2000; 9(1): 11-5. 
[7] $\mathrm{Ng} \mathrm{KBY,} \mathrm{Vanselow} \mathrm{B.} \mathrm{Outbreak} \mathrm{of} \mathrm{surra} \mathrm{in} \mathrm{horses} \mathrm{and} \mathrm{the} \mathrm{pathogenesis} \mathrm{of} \mathrm{the} \mathrm{anaemia.} \mathrm{Kajian} \mathrm{Veterinar} \mathrm{1978;} \mathrm{10(2):} \mathrm{88-98.}$

[8] Ikede BO, Fatimah I, Sharifuddin W, Bongsu TA. Clinical and pathological features of natural Trypanosoma evansi infections in ponies in West Malaysia. Trop Vet 1983; 1(3): 151-7.

[9] Hörchner F, Schönefeld A, Wüst B. Experimental infection of horses with Trypanosoma evansi. I. Parasitological and clinical results. Ann Soc Belg Med Trop 1983; 63(2): 127-35. [PMID: 6615044]

[10] Berlin D, Loeb E, Baneth G. Disseminated central nervous system disease caused by Trypanosoma evansi in a horse. Vet Parasitol 2009; 161(3-4): 316-9.

[http://dx.doi.org/10.1016/j.vetpar.2009.01.030] [PMID: 19251368]

[11] Elshafie EI, Sani RA, Hassan L, Sharma R, Bashir A, Abubakar IA. Seroprevalence and risk factors of Trypanosoma evansi infection in horses in Peninsular Malaysia. Res Vet Sci 2013; 94(2): 285-9. [http://dx.doi.org/10.1016/j.rvsc.2012.09.004] [PMID: 23021152]

[12] Elshafie EI, Sani RA, Hassan L, Sharma R, Bashir A, Abubakar IA. Active infection and morphometric study of Trypanosoma evansi among horses in Peninsula Malaysia. Trop Biomed 2013; 30(3): 444-50. [PMID: 24189674]

[13] Woo PTK. The haematocrit centrifuge technique for the diagnosis of African trypanosomiasis. Acta Trop 1970; 27(4): 384-6. [PMID: 4396363]

[14] Wernery U, Zachariah R, Mumford JA, Luckins T. Preliminary evaluation of diagnostic tests using horses experimentally infected with Trypanosoma evansi. Vet J 2001; 161(3): 287-300. [http://dx.doi.org/10.1053/tvj1.2000.0560] [PMID: 11352486]

[15] Da Silva AS, Zanette RA, Wolkmer P, et al. Diminazene aceturate in the control of Trypanosoma evansi infection in cats. Vet Parasitol 2009; 165(1-2): 47-50.

[http://dx.doi.org/10.1016/j.vetpar.2009.06.025] [PMID: 19631469]

[16] Tuntasuvan D, Jarabrum W, Viseshakul N, et al. Chemotherapy of surra in horses and mules with diminazene aceturate. Vet Parasitol 2003; 110(3-4): 227-33. [http://dx.doi.org/10.1016/S0304-4017(02)00304-7] [PMID: 12482651]

[17] Pritchard JC, Burn CC, Barr ARS, Whay HR. Haematological and serum biochemical reference values for apparently healthy working horses in Pakistan. Res Vet Sci 2009; 87(3): 389-95. [http://dx.doi.org/10.1016/j.rvsc.2009.05.003] [PMID: 19552930]

[18] Ohaeri CC, Eluwa MC. Abnormal biochemical and haematological indices in trypanosomiasis as a threat to herd production. Vet Parasitol 2011; 177(3-4): 199-202.

[http://dx.doi.org/10.1016/j.vetpar.2011.02.002] [PMID: 21382664]

[19] Hutchinson OC, Picozzi K, Jones NG, et al. Variant Surface Glycoprotein gene repertoires in Trypanosoma brucei have diverged to become strain-specific. BMC Genomics 2007; 8: 234. [http://dx.doi.org/10.1186/1471-2164-8-234] [PMID: 17629915]

[20] Silva RAMS, Herrera HM, Domingos LBDS, Ximenes FA, Dávila AMR. Pathogenesis of Trypanosoma evansi infection in dogs and horses: Hematological and clinical aspects. Cienc Rural 1995; 25(2): 233-8. [http://dx.doi.org/10.1590/S0103-84781995000200010]

[21] Cadioli FA, Marques LC, Machado RZ, Alessi AC, Aquino LPCT, Barnabe PA. Experimental Trypanosoma evansi infection in donkeys: Hematological, biochemical and histopathological changes. Arq Bras Med Vet Zootec 2006; 58(5): 749-56. [http://dx.doi.org/10.1590/S0102-09352006000500008]

[22] Da Silva AS, Garcia Perez HA, Costa MM, et al. Horses naturally infected by Trypanosoma vivax in southern Brazil. Parasitol Res 2011; 108(1): 23-30. [http://dx.doi.org/10.1007/s00436-010-2036-2] [PMID: 20820805]

[23] Assoku RKG. Immunological studies of the mechanism of anaemia in experimental Trypanosoma evansi infection in rats. Int J Parasitol 1975; 5(2): 137-45.

[http://dx.doi.org/10.1016/0020-7519(75)90020-X] [PMID: 1116896]

[24] Wolkmer P, da Silva AS, Traesel CK, et al. Lipid peroxidation associated with anemia in rats experimentally infected with Trypanosoma evansi. Vet Parasitol 2009; 165(1-2): 41-6. [http://dx.doi.org/10.1016/j.vetpar.2009.06.032] [PMID: 19628334]

[25] Goossens B, Osaer S, Kora S, Ndao M. Haematological changes and antibody response in trypanotolerant sheep and goats following experimental Trypanosoma congolense infection. Vet Parasitol 1998; 79(4): 283-97. [http://dx.doi.org/10.1016/S0304-4017(98)00171-X] [PMID: 9831952]

[26] Stephen LE. Trypanosomiasis: A veterinary perspective. Oxford: Pergamon Press 1986.

[27] Wellde BT, Kovatch RM, Chumo DA, Wykoff DE. Trypanosoma congolense: Thrombocytopenia in experimentally infected cattle. Exp Parasitol 1978; 45(1): 26-33. [http://dx.doi.org/10.1016/0014-4894(78)90041-3] [PMID: 668836] 
[28] Weiss DJ, Wardrop KJ. Schalm's Veterinary Hematology. $6^{\text {th }}$ ed. Oxford: Wiley-Blackwell, Iowa, USA 2010.

[29] Ngaira JM, Nantulya VM, Musoke AJ, Hirumi K. Phagocytosis of antibody-sensitized Trypanosoma brucei in vitro by bovine peripheral blood monocytes. Immunology 1983; 49(2): 393-400. [PMID: 6852873]

[30] Egbe-Nwiyi TN, Antia RE. The effect of trypanocidal drug treatment on the haematological changes in Trypanosoma brucei brucei infected splenectomised dogs. Vet Parasitol 1993; 50(1-2): 23-33.

[http://dx.doi.org/10.1016/0304-4017(93)90004-7] [PMID: 8291194]

[31] Verma BB, Gautam OP, Malik PD. Trypanosoma evansi: Therapeutic efficacy of diminazine aceturate in crossbred calves, Bos taurus and B. indicus. Exp Parasitol 1976; 40(3): 406-10. [http://dx.doi.org/10.1016/0014-4894(76)90107-7] [PMID: 976424]

\section{(C) 2018 Elshafie et al.}

This is an open access article distributed under the terms of the Creative Commons Attribution 4.0 International Public License (CC-BY 4.0), a copy of which is available at: https://creativecommons.org/licenses/by/4.0/legalcode. This license permits unrestricted use, distribution, and reproduction in any medium, provided the original author and source are credited. 